\title{
Feeding Activity and Growth Performance of Shrimp Post Larvae Litopenaeus vannamei Under Light and Dark Condition
}

\author{
Noorsyarinah Sanudin ${ }^{1}$, Audrey Daning Tuzan ${ }^{1} \&$ Annita Seok Kian Yong ${ }^{1}$ \\ ${ }^{1}$ Borneo Marine Research Institute, Universiti Malaysia Sabah, Sabah, Malaysia \\ Correspondence: Annita Seok Kian Yong, Borneo Marine Research Institute, Universiti Malaysia Sabah, 88400, \\ Kota Kinabalu Sabah, Malaysia. Tel: 60-88-320-000. E-mail: annitay@ums.edu.my
}

Received: June 21, 2014 Accepted: August 18, 2014 Online Published: October 15, 2014

doi:10.5539/jas.v6n11p103

URL:http://dx.doi.org/10.5539/jas.v6n11p103

\begin{abstract}
The present study was conducted to elucidate the effects of light and dark condition on the feeding activity of shrimp, Litopenaeus vannamei. Examination on the ingestion rate of shrimps at different sizes $(0.5,1.0$ and 1.5 cm total length, TL) under light and dark condition was conducted using newly hatched frozen Artemia nauplii. For each condition, shrimp were let to ingest known number of Artemia nauplii for 30 minutes, thereafter the remaining Artemia nauplii was counted. For the observation of eye structures under light and dark conditions, $1.0 \mathrm{~cm}$ TL shrimps were preserved in Bouin's solution for histological observation. Another feeding trial was conducted to examine the growth performance and survival of shrimps (initial size $1.0 \pm \mathrm{cm}$, TL) under different photoperiod regimes (24 hours dark: 24D, 24 hours light: 24L and 12 hours light and dark: 12LD) for three weeks. Results showed that, the $0.5 \mathrm{~cm}$ TL shrimp significantly ingested more Artemia nauplii under light condition compared to dark condition $(P=0.000)$. The 1.0 and $1.5 \mathrm{~cm}$ TL shrimps consumed Artemia naulplii equally under both conditions. The shrimp attained a complete eye structure which can be differentiated into crystalline cone, clear zone, rhabdom and fasciculated zone at $1.0 \mathrm{~cm}$ TL. This study also showed that growth $(P$ $=0.557)$ and survival $(P=0.686)$ of shrimps did not vary significantly among different photoperiod. This study suggests that the feeding activity of the smallest shrimp $(0.5 \mathrm{~cm} \mathrm{TL})$ is affected by light condition. However, feeding activity, growth and survival of bigger sized shrimp ( $>1.0 \mathrm{~cm} \mathrm{TL})$ were not affected by light and photoperiod regimes.
\end{abstract}

Keywords: dark condition, ingestion, growth performance, light condition, Litopenaeus vannamei, photoperiod

\section{Introduction}

The Pacific white shrimp, Litopenaeus vannamei is originated from the Western Pacific coast of Latin America stretching from the south of Peru to the north of Mexico (Briggs, Smith, Subasinghe, \& Philip, 2004). This species was introduced commercially into China and Taiwan in 1996 and other coastal Asian countries started to culture this species in early 2000 (Briggs et al., 2004). Since then, L. vannamei became one of the important penaeid species farmed worldwide (Balakrishnan et al., 2011).

Light is considered to be one of the most important factors in directing locomotor rhythm in crustacean (Hughes, 1968). In marine fish, feeding activity is mostly assisted by visual receptor in light environment. While other sensory organs such as lateral line play role in detecting prey under dim or dark condition. Several studies on ingestion experiments of crustacean species are performed to investigate the optimum food density (Yufera, Rodriguez \& Lubian, 1984; Chu \& Shing, 1986; Zhang, Lin \& Creswell, 1998) and feeding schedule (Vega-Perez, Ara, Liang \& Pedreira, 1996; Barros \& Valenti., 2003; Martin et al., 2006). However, limited information available on the feeding activity of $L$. vannamei under light and dark condition and the sensory organ/s that are responsible in food searching under those conditions. Shrimp has compound eyes which are the general characteristic of eutrhopods (Schoenemann, 2013). The compound eyes are believed to have a complicated structure (Cronin \& Jinks, 2001) which composes of repetitively identical visual units called ommatidia. Each of the ommatidium composed of optical structures of cornea, lens and crystalline cone. The ommatidium is stacked on top of rhabdoms (Schoenemann, 2013; Cronin, 1986; Cronin \& Jinks, 2001). Rhabdom is a light-guiding structure (Land \& Fernald, 1992) which is formed by 7-8 retinular cells (Schoenemann, 2013; Cronin, 1986; Cronin \& Jinks, 2001; Martin, Crandall, \& Felder, 2009). In some species of crustacean such as the rock lobster Jasus edwardsii, the size and shape of the rhabdom are affected by dark or light adaptation (Meyer-Rochow, 2001). While some species such as Penaeus monodon, the size and shape of the rhabdom did not change as an effect to light or dark adaptation. However, the position of the screening pigment granules were changed, as in light condition the screening pigment granules insulating the rhabdom 
while under dark condition it is migrated away from the edge of the rhabdom (Matsuda \& Wilder, 2010).

In shrimp farming, abiotic factors such as light and photoperiod are believed to play important roles in promising successful grow-out period. Light is able to influence the behaviour (Sulkin, 1984; Minagawa \& Murano, 1993), physiology (Ravi \& Manisseri, 2012), cannibalism (Hecht \& Pienaar, 1993) and molting (Vijayan \& Diwan, 1995) of decapods larvae. The effects of photoperiod on larval survival and growth have been studied in several species of crustacean and the results varied with species. Study on the larvae of marine blue swimmer crab, Portunus pelagicus at zoea until megalopa stage showed no significant difference on survival under different photoperiod regimes (6L:18D, 12L:12D, 18L:6D) (Ravi \& Manisseri, 2012). Gardner and Meguire (1998) also reported the insignificant difference of survival rate on the zoea of the Australian giant crab, Pseudocarcinus gigas reared under different photoperiod regimes (0L:24D, 6L:18D, 12L:12D, 18L:6D, 24L:0D). The early juvenile stage, $26-27 \mathrm{~mm}$ total length (TL) of Penaeus indicus also revealed no significant difference on growth, cultured under different photoperiod regimes (24L:0D, 12L:12D, 0L:24D) (Vijayan \& Diwan, 1995). Despite the insignificant results, Hoang, Barchiesis, Lee, Keenan and Marsden (2003) stated that photoperiod had significant effect on the growth of banana prawn, Penaeus merguinses juveniles (3.13-3.77 g, initial weight) but not on the survival rate.

There is lack of information on the effects of light condition on the feeding activity of $L$. vannamei. Furthermore, the varied results of different photoperiod on the growth and survival of shrimp have led to this present study. This study was conducted to examine the influence of light and dark condition on the feeding activity and the different photoperiod regimes on growth and survival of $L$. vannamei.

\section{Materials and Methods}

\subsection{Experiment on Ingestion of Post Larvae Under Light and Dark Condition}

The shrimp (PL3) were obtained from a private hatchery and acclimatized to experimental conditions in shrimp hatchery of Borneo Marine Research Institute, Universiti Malaysia Sabah. The shrimps were fed with Artemia nauplii until they reached $0.5 \mathrm{~cm}$ of TL (PL 5).Then, shrimp with the size of $0.5,1.0$ and $1.5 \mathrm{~cm}$ TL were used in the ingestion experiment, fed with frozen Artemia nauplii under light and dark conditions. The ingestion experiments under light and dark condition were alternately conducted in a dark room which equipped with fluorescent lamps (Power-Glo lamp, Hagen, Canada). For light condition the light intensity used was $1400 \pm$ 339.19 lx (measured by Light meter Model LT300, Extech Instrument, USA) while for dark condition the lights were switched off. The light intensity used in this experiment was slightly higher with the next experiment without much difference. In order to maintain the temperature, air conditioner and a mechanical fan was switched on during the ingestion experiment under light condition to ventilate the room. While the air conditioner and mechanical fan was switched off under dark condition. Prior to the experiment, the shrimp were starved for 12 hours before the feeding experiments. Thirty shrimp of each size were kept individually in $500 \mathrm{ml}$ beakers. The shrimps were then acclimatized to light or dark condition for 30 minutes. Thereafter, known numbers of frozen Artemia nauplii were placed into the beaker and the shrimps were left to feed for 30 minutes. The shrimp were subsequently anesthetized by putting an ice cube into the beakers followed by adding few drops of $15 \%$ paraformaldehyde into the beakers in order to stop the ingestion within a couple of minutes and left over Artemia nauplii were counted. This trial was repeated for different sized shrimp following the condition as stated in Table 1. Ingestion rate of Artemia nauplii was estimated as follows:

$$
\text { Ingestion rate }(\%)=\left[\left(\mathrm{A}_{\mathrm{i}}-\mathrm{A}_{\mathrm{f}}\right) / \mathrm{A}_{\mathrm{i}}\right] \times 100
$$

Where $\mathrm{A}_{\mathrm{i}}$ is the initial number of given Artemia nauplii and $\mathrm{A}_{\mathrm{f}}$ is the number of uneaten Artemia nauplii. For 1.0 $\mathrm{cm}$ TL shrimp, the shrimps were preserved in Bouin's solution for observation on the eye structure after adaptations under light and dark conditions. The samples were dehydrated with an ascending series of ethanol and cleared with xylene. After that, the samples were embedded in paraffin, cut into $6 \mu \mathrm{m}$ thick sections and lastly, stained with hematoxylin and eosin (Yahaya et al., 2011; Matsuda \& Wilder, 2010; Mukai, 2006) before observation under light microscope (Eclipse $80_{\mathrm{i}}$, Nikon, Japan).

Table 1. Number of Artemia nauplii given to different sized shrimp

\begin{tabular}{ll}
\hline Total length $(\mathrm{cm})$ & Number of Artemia nauplii \\
\hline 0.5 & 15 \\
1.0 & 30 \\
1.5 & 60 \\
\hline
\end{tabular}




\subsection{Experiment on Growth Performance of Post Larvae Under Different Photoperiod Regimes}

The shrimp size of $1.0 \mathrm{~cm}$ TL with the initial body weight $15.00 \pm 3.00 \mathrm{mg}$ was used for feeding trial under different photoperiod regimes. Groups of 30 individual of shrimp $\left(6\right.$ individuals $\left.\mathrm{L}^{-1}\right)$ were introduced into $7 \mathrm{~L}$ plastic aquaria where all sides of the walls including the bottom were wrapped with black plastic sheets and filled with $5 \mathrm{~L}$ of seawater. The shrimp were reared under three photoperiod regimes which were continuously dark conditions (24 hours dark, 24D), continuously light conditions (24 hours light, 24L) and natural diurnal cycle (12 hours light and 12 hours dark, 12LD). Each treatment was done in five replicates. For the 12LD and 24L, the shrimps were exposed to $1368 \pm 235 \mathrm{~lx}$ of light intensity. Meanwhile, under continuous dark conditions no light was provided. The shrimps were fed with extruded commercial pellet (starter crumble number $3,42 \%$ protein, 6\% lipid, Cargill, Malaysia) twice daily in the morning (0900) and evening (1600) at a feeding rate of 15 $\%$ of total biomass. Every morning, $20 \%$ of the water was changed and the water temperature during the experiments was recorded in the range of $28.0-29.0{ }^{\circ} \mathrm{C}$. For continuous dark condition, the aquaria were exposed to light for about 10 minutes in order to change the water and to feed the shrimp. The experiment was conducted for three weeks and routine body weight measurement was conducted once a week to estimate the growth performance. The weight of the shrimps was weighed individually to the nearest $0.0001 \mathrm{~g}$ using the analytical balance (model PA214C, OHAUS Pioneer, USA). At the end of the rearing trial, numbers of shrimp survived were recorded. Weight gain, food conversion ratio, specific growth rate and survival rate were determined as follows:

$$
\text { Weight gain }(\%)=\left[\left(\mathrm{W}_{\mathrm{f}}-\mathrm{W}_{\mathrm{i}}\right) / \mathrm{W}_{\mathrm{i}}\right] \times 100
$$

Food conversion ratio, FCR $=$ total dry feed intake $(\mathrm{g}) /$ weight gain $(\mathrm{g})$

Specific growth rate, SGR $(\% /$ day $)=\left[\left(\operatorname{lnW}_{\mathrm{f}}-\ln \mathrm{W}_{\mathrm{i}}\right) /\right.$ day $] \times 100$

Survival rates $(\%)=($ final number of shrimp/initial number of shrimp $) \times 100$

Where the $\mathrm{W}_{\mathrm{i}}$ is the initial weight $(\mathrm{mg})$ and $\mathrm{W}_{\mathrm{f}}$ is the final weight $(\mathrm{mg})$ of the shrimps (Ju, Deng, \& Dominy, 2012; Kim, Rahimnejad, Kim, \& Lee, 2013).

\subsection{Statistical Analysis}

Data obtained on the ingestion rates of frozen Artemia nauplii, were statistically analyzed with t-test (Statistical package of social sciences, SPSS ver. 21, USA). Growth, survivals and feed utilization of shrimp were analyzed with One-way analysis of variance.

\section{Results}

\subsection{Ingestion Experiments}

The frozen Artemia nauplii ingested by the L. vannamei at different sizes under light and dark condition is presented in Table 2. Smallest sized shrimp $(0.5 \mathrm{~cm}$ TL) significantly ingested more frozen Artemia nauplii under light condition compared to dark condition $(P=0.000)$. However, the ingestion rate of frozen Artemia nauplii did not differed significantly under light and dark condition by $1.0 \mathrm{~cm} \mathrm{TL}(P=0.576)$ and $1.5 \mathrm{~cm}$ TL $(P$ $=0.506)$ of shrimp.

Table 2. Ingestion rates of frozen Artemia nauplii by L. vannamei under light and dark condition

\begin{tabular}{ccc}
\hline \multirow{2}{*}{ Total length $(\mathrm{cm})$} & \multicolumn{2}{c}{ Ingestion rates $(\%)$ of frozen Artemia nauplii } \\
\cline { 2 - 3 } & Light & Dark \\
\hline 0.5 & $62.00 \pm 15.08^{\mathrm{a}}$ & $39.33 \pm 13.03^{\mathrm{b}}$ \\
1.0 & $88.11 \pm 13.52^{\mathrm{a}}$ & $89.78 \pm 9.01^{\mathrm{a}}$ \\
1.5 & $67.33 \pm 25.45^{\mathrm{a}}$ & $71.28 \pm 19.89^{\mathrm{a}}$
\end{tabular}

*Values expressed mean \pm standard deviation, and values with different letters within the same row indicate significant value $(P<0.05)$.

Histological observations on the eye of $1.0 \mathrm{~cm}$ TL shrimp under light and dark conditions are shown in Figure 1. It is found that there are four optical properties observed which are crystalline cone, clear zone, rhabdom and fasciculated zone. It showed that, the eyes were able to adapt to light and dark condition. This is based on the position of the screening pigment granules in the rhabdom. Under light condition, screening pigment granules moved upward insulating the rhabdom while the screening pigment granules migrated away from the edge of the rhabdom under dark condition. 

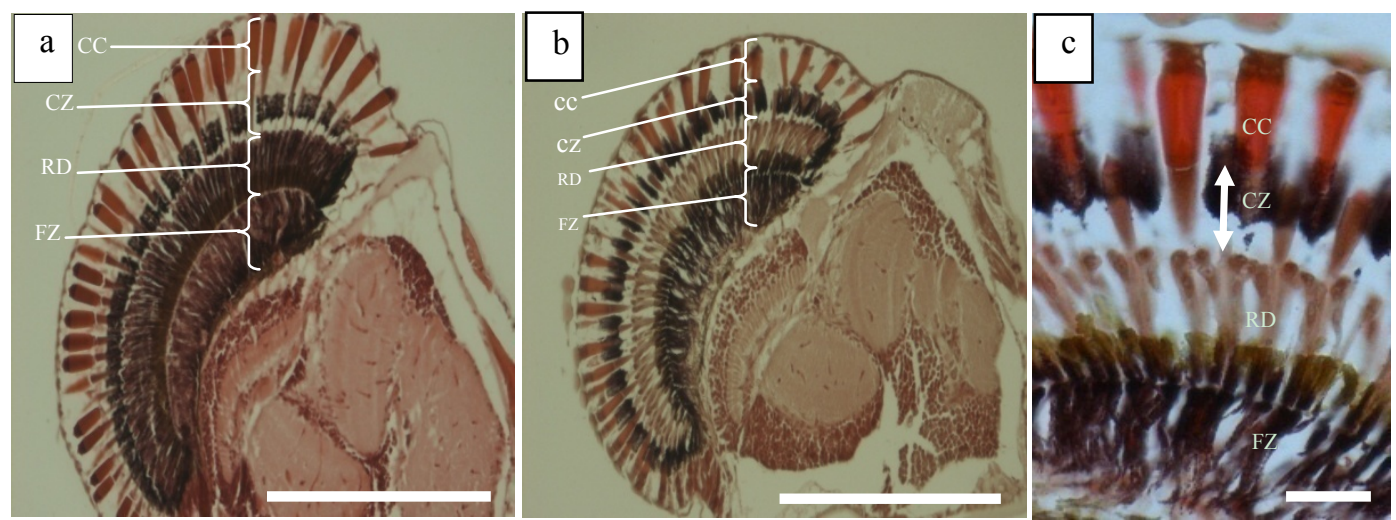

Figure 1. Histological observation on the eye of $1.0 \mathrm{~cm}$ TL shrimp, a) kept under light condition. Scale bar 100 $\mu \mathrm{m}$. b) kept under dark condition. Scale bar $100 \mu \mathrm{m}$. c) a portion of eye of the shrimp, arrow shows the area of clear zone. Scale bar $20 \mu \mathrm{m}$. CC, crystalline cone; CZ, clear zone; RD, rhabdom; FZ, fasciculated zone

\subsection{Post Larval Rearing Under Different Photoperiod}

The average body weight of the shrimp after three weeks of rearing period showed no significant different among the treatment groups $(P=0.557)$ (Table 3$)$. The body weight gain of shrimp under $24 \mathrm{~L}$ was $810.64 \%$ followed by 24D, 12LD with the value of $799.71 \%$ and $778.12 \%$ respectively. Results of SGR $(P=0.495)$ and FCR $(P=0.890)$ also showed similar trend as weight gain without significant difference. Survival rate of shrimp also showed no significant different among the groups $(P=0.686)$.

Table 3. Growth performance and feed utilization of $L$. vannamei

\begin{tabular}{ccccccc}
\hline Photoperiod & $\begin{array}{c}\text { Initial weight } \\
(\mathrm{mg} / \text { individual })\end{array}$ & $\begin{array}{c}\text { Final weight } \\
(\mathrm{mg} / \text { individual })\end{array}$ & $\begin{array}{c}\text { Weight gain } \\
(\%)\end{array}$ & FCR & $\begin{array}{c}\text { SGR } \\
(\% / \text { day })\end{array}$ & $\begin{array}{c}\text { Survival } \\
\text { rates }(\%)\end{array}$ \\
\hline 24D & $15 \pm 3.00$ & $133 \pm 35.00$ & $799.71 \pm 526.28$ & $0.89 \pm 0.05$ & $9.98 \pm 0.27$ & $95.33 \pm 1.83$ \\
24L & $15 \pm 3.00$ & $138 \pm 32.00$ & $810.64 \pm 430.54$ & $0.87 \pm 0.05$ & $10.04 \pm 0.22$ & $93.33 \pm 4.71$ \\
12LD & $15 \pm 3.00$ & $131 \pm 35.00$ & $778.12 \pm 233.25$ & $0.90 \pm 0.05$ & $9.87 \pm 0.12$ & $94.67 \pm 3.80$ \\
\hline
\end{tabular}

\section{Discussion}

This present study showed that different lighting condition (light and dark) affects the feeding activity of the smallest shrimp $(0.5 \mathrm{~cm} \mathrm{TL})$ based on the ingestion rate of frozen Artemia nauplii. The smallest shrimp ingested significantly more frozen Artemia nauplii under light condition compared to dark condition. The ingestion rates of frozen Artemia naupliiunder light condition was 1.58 times higher than under dark condition, suggest that vision is important in the feeding activity of the shrimp in the light phase. However, dependency on eyes in hunting food decreased with the shrimp growth. The insignificant results of the ingested frozen Artemia nauplii by 1.0 and $1.5 \mathrm{~cm}$ TL of shrimp under light and dark condition suggest that the feeding activity of the shrimp was not affected by the lighting condition. This indicates that other sensory organs than eyes are also responsible in food searching especially under dark condition. Setae are part of sensory system of shrimp which either function as mechanosensory, chemosensory or both (Garm, Hallberg, \& Hoeg, 2003). These setae can be found around the appendages of the shrimp such as uropods, pleopods and antennules scales (Chan, Rankin, \& Keeley, 1988). In this study, frozen Artemia was provided, and hence no vibration was produced in water column during the feeding. However, the ability of shrimps to detect and consume frozen Artemia nauplii particularly under dark condition may be due to the functionality of the chemosensory of the setae. This study is in agreement with You et al. (2006) reported that odours are mainly used for food detection by the juvenile of $L$. vannamei due to the ability to ingest food under dark condition. Kumlu (1999) also stated that decapods larvae were found to use other sensory organs than eyes in hunting for prey and stated that dark condition did not affect the growth of the larvae under longer dark hour.

Although the shrimp used other sensory organ in detecting food, the eyes were remarkably found to be well adapted to light and dark condition at $1.0 \mathrm{~cm}$ TL of shrimp. Through the histological observation, it is found that clear zone is present in the eye of $1.0 \mathrm{~cm}$ TL of shrimp. Clear zone is a region devoid of pigment or a gap between the dioptric apparatus (cornea and crystalline cone) and the rhabdom (Cronin \& Porter, 2008; 
Meyer-Rochow, 2001). The function of clear zone is to improve crustacean vision in dim light environment (Matsuda \& Wilder, 2010; Meyer-Rochow, 2001). Thus, the eyes of the shrimp were able to adapt well especially under dark condition. This is based on the rhabdom part of the eye which is formed by 7-8 retinular cells that is capable of sensing light (Schoenemann, 2013; Cronin, 1986; Cronin \& Jinks, 2001; Martin et al., 2009). Under light condition, screening pigment granules moved upward insulating the rhabdom while the screening pigment granules migrated away from the edge of the rhabdom under dark condition. Juvenile and sub-adult of $L$. vannamei were also having the ability to change their optical properties of the eyes by light or dark adaptation through the position of the screening pigment granules (Matsuda \& Wilder, 2010). Since the eyes are able to adapt under light or dark condition, eyes might play a role in food searching under light condition for the 1.0 and $1.5 \mathrm{~cm}$ TL of shrimp. Other sensory organs which are setae may also function for food hunting under light and dark condition.

This present study also showed that the growth, survival and feed utilization of $L$. vannamei were not significantly affected by the photoperiod regimes. This might be due to the ability of the shrimp to detect and consume food under light and dark condition which has been showed through the ingestion experiment. Some researchers found that the ability to consume feed in any lighting regime might not affect the survival of decapods larvae (Gardner \& Maguire, 1998). Other studies also revealed the insignificant result of different photoperiod regimes on the survival and growth of crustacean species. Ravi and Manisseri (2012) revealed that the survival rate of blue swimmer crab, Portunus pelagicus larvae was not affected by different photoperiod regime (6L:18D, 12L:12D, 18L:6D). Survival rate of the zoea of Australian giant crab, Pseudocarcinus gigas were also reported to have no significant effect after being cultured under different photoperiod regimes (0L:24D, 6L:18D, 12L:12D, 18L:6D, 24L:0D) (Gardner \& Maguire, 1998). Matsuda, Abe and Tanaka (2012) also revealed the insignificant result of different photoperiod (10L:14D, 12L:12D, 14L:10D) on the growth of phyllosoma larvae of the Japanese spiny lobster, Panulirus japonicus.

Overall, this present study showed that the light conditions affected the feeding activity of the smallest shrimp $(0.5 \mathrm{~cm} \mathrm{TL})$, where they depend more on eyes to search for food. As the shrimp grow (up to 1.0 and $1.5 \mathrm{~cm} \mathrm{TL}$ ), light or dark conditions did not influence the feeding activity as well as the growth performance, survival and feed utilization. The eyes were found to be well adapted to light and dark condition and have a complete structure at size of $1.0 \mathrm{~cm} \mathrm{TL}$.

\section{Acknowledgements}

The authors are grateful for logistical supports provided by Borneo Marine Research Institute hatchery of Universiti Malaysia Sabah and experiment shrimps provided by Syarikat Pantai Barat Laut Sdn. Bhd, Kota Kinabalu. The study was partially funded by the Ministry of Higher Education Malaysia under the Fundamental Research Grant Scheme.

\section{References}

Balakrishnan, G., Peyail, S., Ramachandran, K., Theivasigamani, A., Savji, K. A., Chokkaiah, M., \& Nataraj, P. (2011). Growth of cultured white leg shrimp Litopenaeus vannamei (Boone 1931) in different stocking density. Advanced in Applied Science Research, 2(3), 107-113.

Barros, H. P., \& Valenti, W. C. (2003). Food intake of Macrobrachium rosenbergii during larval development. Aquaculture, 216, 165-176. http://dx.doi.org/10.1016/S0044-8486(02)00505-7

Briggs, M., Smith, S. M., Subasinghe, R., \& Phillips, M. (2004). Introduction and movement of Penaeus vannamei and Penaeus stylirostris in Asia and the Pacific. Bangkok: Food and Agricultural Organization.

Chan, S. M., Rankin, S. M., \& Keeley, L. L. (1988). Characterization of the molt stages in Penaeus vannamei: setogenesis and hemolymph levels of total protein, ecdysteroids and glucose. Biol Bull, 175, 185-192.

Chu, K. H., \& Shing, C. K. (1986). Feeding behavior of the shrimp, Metapenaeus ensis, on Artemia nauplii. Aquaculture, 58, 175-184. http://dx.doi.org/10.1016/0044-8486(86)90083-9

Cronin, T. W. (1986). Optical design and evolutionary adaptation in crustacean compound eyes. Journal of Crustacean Biology, 6, 1-23.

Cronin, T. W., \& Jinks, R. N. (2001). Ontogeny of vision in marine crustacean. Amer. Zool, 41, 1098-1107.

Cronin, T. W., \& Porter, M. L. (2008). Exceptional variation on a common theme: the evolution of crustacean compound eyes. EvoEdu Outreach. http://dx.doi.org/10.1007/s12052-008-0085-0

Gardner, C., \& Maguire, G. B. (1998). Effect of photoperiod and light intensity on survival, development and cannibalism of larvae of the Australian giant crab Pseudocarcinus gigas (Lamarck). Aquaculture,165, 51-63.

Garm, A., Hallberg, E., \& Hoeg, J. T. (2003). Role of maxilla 2 and its setae during feeding in the shrimp 
Palaemon adspersus (Crustacea: Decapoda). Biological Bulletin, 204, 126-137.

Hecht, T., \& Pienaar, A. G. (1993). A review of cannibalism and its implications in fish larviculture. Journal of the World Aquaculture Society, 24, 246-261. http://dx.doi.org/10.1111/j.1749-7345.1993.tb00014.x

Hoang, T., Barchiesis, M., Lee, S. Y., Keenan, C. P., \& Marsden, G. E. (2003). Influences of light intensity and photoperiod on moulting and growth of Penaeus merguiensis cultured under laboratory conditions. Aquaculture, 216, 343-354. http://dx.doi.org/10.1016/S0044-8486(02)00460-X

Hughes, D. A. (1968). Factors controlling emergence of pink shrimp (Penaeus duorarum) from the substrate. Biological Bulletin, 134, 48-59.

Ju, Z. Y., Deng, D., \& Dominy, W. (2012). A deffated microalgae (Haematococcus pluvialis) meal as a protein ingredient to partially replace fishmeal in diets of Pacific white shrimp (Litopeneaus vannamei, Boone, 1931). Aquaculture, 354-355, 50-55. http://dx.doi.org/10.1016/j.aquaculture.2012.04.028

Kim, S., Rahimnejad, S., Kim, K., \& Lee, K. (2013). Partial replacement of fish meal with Spirulina pacifica in diets for parrot fish (Oplegnathus fasciatus). Turkish Journal of Fisheries and Aquatic Sciences, 13, 197-204. http://dx.doi.org/10.4194/1303-2712-v13_2_01

Kumlu, M. (1999). Feeding and digestion in larval decapods crustaceans. Turkish Journal of Biology, 23, 215-229.

Land, M. F., \& Fernald, R. D. (1992). The evolution of eyes. Annu. Rev. Neurosci, 15, 1-29. http://dx.doi.org/10.1146/annurev.ne.15.030192.000245

Martin, L., Arenal, A., Fajardo, J., Pimentel, E., Hidalgo, L., Pacheco, M., ... Santiesteban, D. (2006). Complete and partial replacement of Artemia nauplii by Moina micrura during early postlarval culture of white shrimp (Litopenaeus schmitti). Aquaculture Nutrition, 12, 89-96.

Martin, J. N., Crandall, K. A., \& Felder, D. L. (2009). Crustacean issues 18; Decapod crustacean phylogenetics.United States of America, Taylor \& Francis Group.

Matsuda, H., Abe, F., \& Tanaka, S. (2012). Effect of photoperiod on metamorphosis from phyllosoma larvae to puerulus postlarvae in the Japanese spiny lobster Panulirus japonicus. Aquaculture, 326-329, 136-140. http://dx.doi.org/10.1016/j.aquaculture.2011.11.027

Matsuda, K., \& Wilder, M. N. (2010). Difference in light perception capability and spectral response between juveniles and sub-adults of the whiteleg shrimp Litopenaeus vannamei as determined by electroretinogram. Fisheries Science, 76, 633-641. http://dx.doi.org/10.1007/s12562-010-0253-3

Meyer-Rochow, V. B. (2001). The crustacean eye: dark/light adaptation, polarization sensitivity, flicker fusion frequency, and photoreceptor damage. Zoological Science, 18, 1175-1197. http://dx.doi.org/10.2108/zsj.18.1175

Minagawa, M., \& Murano, M. (1993). Larval feeding rhythms and food consumption by the red frog crab Ranina ranina (Decapoda, Raninidae) under laboratory conditions. Aquaculture, 113, 251-260.

Mukai, Y. (2006). Role of free neuromasts in larval feeding of willow shiner Gnathopogon elongates caerulescensTeleostei, Cyprinidae. Fisheries Science, 72, 705-709.

Ravi, R., \& Manisseri, M. K. (2012). The effect of different $\mathrm{pH}$ and photoperiod regimes on the survival rate and development period of the larvae of Portunus pelagicus (Decapoda, Brachyura, Portunidae). Iranian Journal of Fisheries Sciences, 12(2) 490-499.

Schoenemann, B. (2013). The eyes of a tiny 'Orsten' crustacean - a compound eye at receptor level?.Vision Research, 76, 89-93. http://dx.doi.org/10.1016/j.visres.2012.10.013

Sulkin, S. D. (1984). Behavioural basis of depth regulation in the larvae of brachyuran crabs. Mar. Ecol. Prog. Ser, 15, 181-205.

Vega-Perez, L. A., Ara, A., Liang, T. H., \& Pedreira, M. M. (1996). Feeding of the planktonic shrimp Lucifer faxoni Borradaile, 1915 (Crustacea: Decapoda) in the laboratory. Rev. Bras. Oceanogr, 44(1), 1-8.

Vijayan, K., \& Diwan, A. D. (1995). Influence of temperature, salinity, pH and light on moulting and growth in the Indian white prawn Penaeus indicus (Crustacea: Decapoda: Penaeida) under laboratory conditions. Asian Fish. Sci,8, 63-72.

Yahaya, S., Lim, L. S., Shaleh, S. R. M., Mukai, Y., Anraku, K., \& Kawamura, G. (2011). Ontogenetic eye development and related behavioural changes in larvae and juveniles of barramundi Lates calcarifer (Bloch). Marine and Freshwater Behaviour and Physiology, 44, 339-348. http://dx.doi.org/10.1080/10236244.2011.626250 
You, K., Yang, H., Liu, Y., Liu, S., Zhou, Y., \& Zhang, T. (2006). Effects of different light sources and illumination methods on growth and body color of shrimp Litopeneaus vannamei. Aquacutlture, 252, 557-565. http://dx.doi.org/10.1016/j.aquaculture.2005.06.041

Yufera, M., Rodriguez, A., \& Lubian, L. M. (1984). Zooplankton ingestion and feeding behavior of Penaeus kerathurus larvae reared in the laboratory. Aquaculture, 42, 217-224. http://dx.doi.org/10.1016/0044-8486(84)90102-9

Zhang, D., Lin, J., \& Creswell, R. L. (1998). Ingestion rate and feeding behavior of the peppermint shrimp Lysmata wudermanni on Artemia nauplii. Journal of the World Aquaculture Society, 29, 97-103. http://dx.doi.org/10.1111/j.1749-7345.1998.tb00305.x

\section{Copyrights}

Copyright for this article is retained by the author(s), with first publication rights granted to the journal.

This is an open-access article distributed under the terms and conditions of the Creative Commons Attribution license (http://creativecommons.org/licenses/by/3.0/). 